\title{
Physiological relaxation induced by horticultural activity: transplanting work using flowering plants
}

\author{
Min-sun Lee ${ }^{1}$, Bum-jin Park², Juyoung Lee ${ }^{3}$, Kun-tae Park', Ja-hyeong Kuㄴ, Jun-woo Lee ${ }^{2}$, Kyung-ok Oh${ }^{5}$ \\ and Yoshifumi Miyazaki ${ }^{*}$
}

\begin{abstract}
Background: Despite increasing attention and a growing volume of research data, little physiological evidence is available on the benefits of horticultural activity and the different effects on individuals. Therefore, the aim of the present study was to investigate the physiological effects of horticultural activity and to examine how differences in personality alter these effects.

Results: The effects of transplanting real flowers (horticultural activity) and handling artificial flowers (control activity) on human physiological activity were compared. On the first day, eight participants engaged in horticultural activity and another eight in the control activity. On the second day, participants switched roles. Participants' physiological conditions during each activity were assessed by measuring the heart rate and heart rate variability (HRV). Psychological responses, which were measured using a semantic differential rating scale, showed that the horticultural activity promoted comfortable, soothed, and natural feelings, compared to the control activity. Analysis of physiological responses using two-way repeated measures analysis of variance (ANOVA) revealed that sympathetic nervous activity significantly decreased in the late time period (11 to 15 minutes) of horticultural activity only in the type A group.
\end{abstract}

Conclusions: This study supports the fact that the horticultural activity can enhance psychological and physiological relaxation effects, although these physiological effects can differ among individuals with different personalities.

Keywords: Horticultural activity, Therapeutic effects, Heart rate variability, Autonomic nervous activity, Personality difference

\section{Introduction}

Humans have spent most of their evolution in natural environments [1] and have an innate desire to interact with such environments (biophilia hypothesis) [2]. The natural environment plays an important role in health promotion, and theoretical foundations for the positive relationships between human health and natural environments have been developed. The attention recovery theory [3,4] and stress reduction theory [5] support that natural environments effectively facilitate recovery from attentional fatigue and psychological stress.

Increasing attention has been paid to the beneficial effects of nature-related activities, including gardening or

\footnotetext{
* Correspondence: ymiyazaki@faculty.chiba-u.jp

${ }^{1}$ Center for Environment, Health and Field Sciences, Chiba University, Kashiwa, Japan

Full list of author information is available at the end of the article
}

horticultural activity, which is considered a health promoter [6]. To date, various studies have demonstrated that gardening or horticultural activities reduce stress [3] and improve self-esteem, social interactions [7], and cognitive health [8]. Due to these beneficial effects, horticultural activity has often been used in rehabilitation programs for patients with different types of disorder $[9,10]$. It has also been reported that flower decoration, one such typical horticultural activity, can ease negative feelings and enhance cognitive ability [11]. Despite many studies on this subject, little scientific evidence is available on the physiological effects of horticultural activity.

In addition, human responses to external stimuli differ depending on an individual's personality; that is, the important and relatively stable characteristics of a person that account for consistent patterns of behavior [12]. So

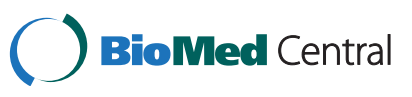


far, most personality studies have been performed by observing external and social behavior; however, recent reports in the field of physiological anthropology support the idea that personality can also be studied by investigating physiological response patterns. Previous experiments have illustrated that human physiological responses to natural stimuli differ according to personality $[13,14]$, indicating the importance of personality studies from the perspective of physiological anthropology. Despite this importance, there are only a few studies that have verified individual differences based on personality in the physiological effects of horticultural activity. Therefore, we examined the differences in the physiological effects among individuals with different personality traits, characterized by a type A and type B behavior pattern $[15,16]$.

The aim of this study was to investigate the psychological and physiological effects of horticultural activity and examine how differences in personality alter these effects from the viewpoint of physiological anthropology.

\section{Methods}

\section{Participants}

The study participants were 16 Korean male university students with an age (mean \pm SD) of $26 \pm 2.1$ years who were non-smokers and had no history of physical or psychological disorders. Alcohol, tobacco, and caffeine intake were prohibited throughout the experimental periods. Prior to the start of experiments, a full explanation was provided on this study, and participants' informed consent was obtained. This study was conducted following the regulations of the Clinical Trials Center, Chungnam National University Hospital, Korea, and the Ethics Committee of the Center for Environment, Health, and Field Sciences, Chiba University, Japan.

\section{Materials}

As a typical horticultural activity, a transplanting activity using real soil and flowers (Chrysanthemum morifolium) was selected. The transplanting method was taught to each participant prior to experiments. The materials used in this study are shown in Figure 1. Transplanting of artificial flowers of almost the same size and weight as real flowers was performed as a control activity. Plastic scraps (approximately 2 to $5 \mathrm{~mm}$ in diameter) instead of soil were used for the control activity. Horticultural and control activities were carried out on the planting bed in a standing position for 15 minutes (Figure 1).

\section{Protocol}

Participants were randomly divided into two groups. On the first day of experiments, the first group $(\mathrm{N}=8)$ carried out horticultural activity, while the second group $(\mathrm{N}=8)$ performed the control activity. On the second day, each group switched activities as a crosscheck.
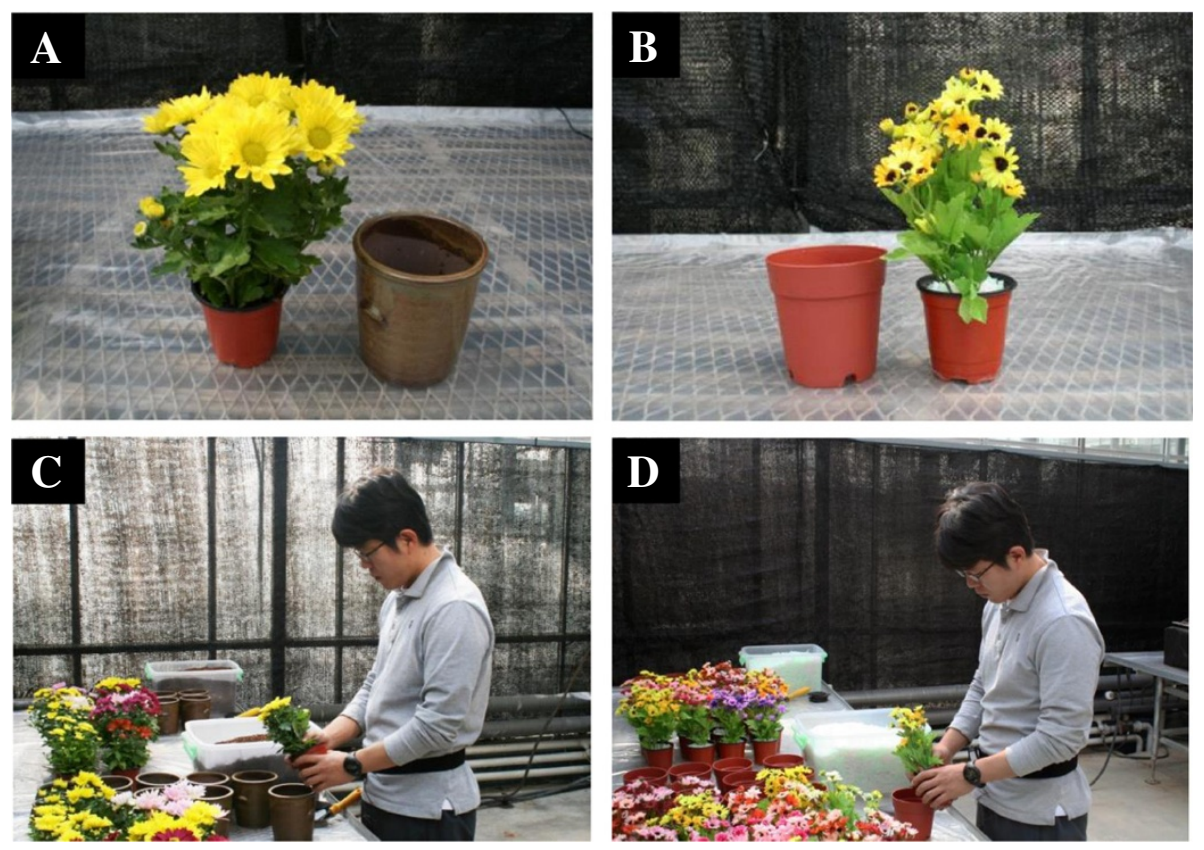

Figure 1 Photographs of materials used in experiments. (A) Real flower (Chrysanthemum); (B) artificial flower; (C) a subject doing horticultural activity; (D) a subject doing control activity. 


\section{Measurements}

Each participant was guided to the experimental room and rested in a seated position for 2 minutes. Then, the participant performed horticultural or control activities for 15 minutes individually. During this activity, heart rate variability (HRV) was continuously measured using a portable electrocardiograph (Activtracer AC-301A; GMS, Tokyo, Japan). After horticultural or control activities, participants rested in a seated position for 2 minutes, followed by subjective evaluation using questionnaires. HRV data were analyzed with maximum entropy methods (MemCalc, GMS, Tokyo, Japan) where low (LF: 0.04 to $0.15 \mathrm{~Hz}$ ) and high frequency (HF: 0.15 to $0.40 \mathrm{~Hz}$ ) components of the power spectrum were calculated based on the R-R interval [17]. The HF component of HRV was used as an index of parasympathetic nervous activity, which increases when in a relaxed state, and the LF/(LF + HF) value of HRV as an index of sympathetic nervous activity, which increases when in a stressed state $[18,19]$. All HRV values were logarized. HRV data were analyzed across three periods of time: early ( 1 to 5 minutes), middle (6 to 10 minutes), and late (11 to 15 minutes). Self-report-type questionnaires were administered using a seven-scaled semantic differential (SD) method for the feelings of 'comfortable', 'soothing', and 'natural'.

\section{Personality}

The type A behavior pattern was used to classify personal characteristics, which is one of the most important factors regulating differences in cardiac responses [20-22]. The type A behavior patterns were identified using a brief questionnaire [23] and participants were categorized into two groups: type A $(\mathrm{N}=8)$ and type $\mathrm{B}(\mathrm{N}=8)$.

\section{Statistical analysis}

Two-way repeated measures analysis of variance (ANOVA) was used for the analysis of physiological data, followed by a simple main effect test for the post hoc analysis. The Wilcoxon signed-rank test was performed to verify the statistical differences in the psychological responses. SPSS 21.0 (SPSS Inc., Chicago, IL, USA) was used for statistical analysis, and the differences were considered significant at $P<0.05$.

\section{Results}

There were significant differences in the analysis of subjective evaluation between horticultural and control activities (Figure 2). After 15 minutes of activities, higher scores were seen for the feelings of 'comfortable', 'soothing', and 'natural' in the horticultural activity than in that of the control.

There was no significant difference between horticultural and control activities in the mean values of heart rate, log $(\mathrm{HF})$ and $\log (\mathrm{LF} /(\mathrm{LF}+\mathrm{HF}))$ for all subjects. However, the differences in the sympathetic nervous responses to two different activities (horticultural and control) were found in the type A group, but not in the type B group. For the type A group, the ANOVA of $\log (\mathrm{LF} /(\mathrm{LF}+\mathrm{HF}))$ tended to reveal an interaction effect $\left(\mathrm{F}_{2,14}=3.188, P=0.072\right)$ between the activities (horticultural and control) $\times$ time period (1 to 5, 6 to 10 , and 11 to 15 minutes), and the simple main effect was yielded by the activities in the late time period (11 to 15 minutes; $\mathrm{F}_{1,7}=5.848, P<0.05$; Figure 3 ). However, the type $B$ group revealed no interaction effect.

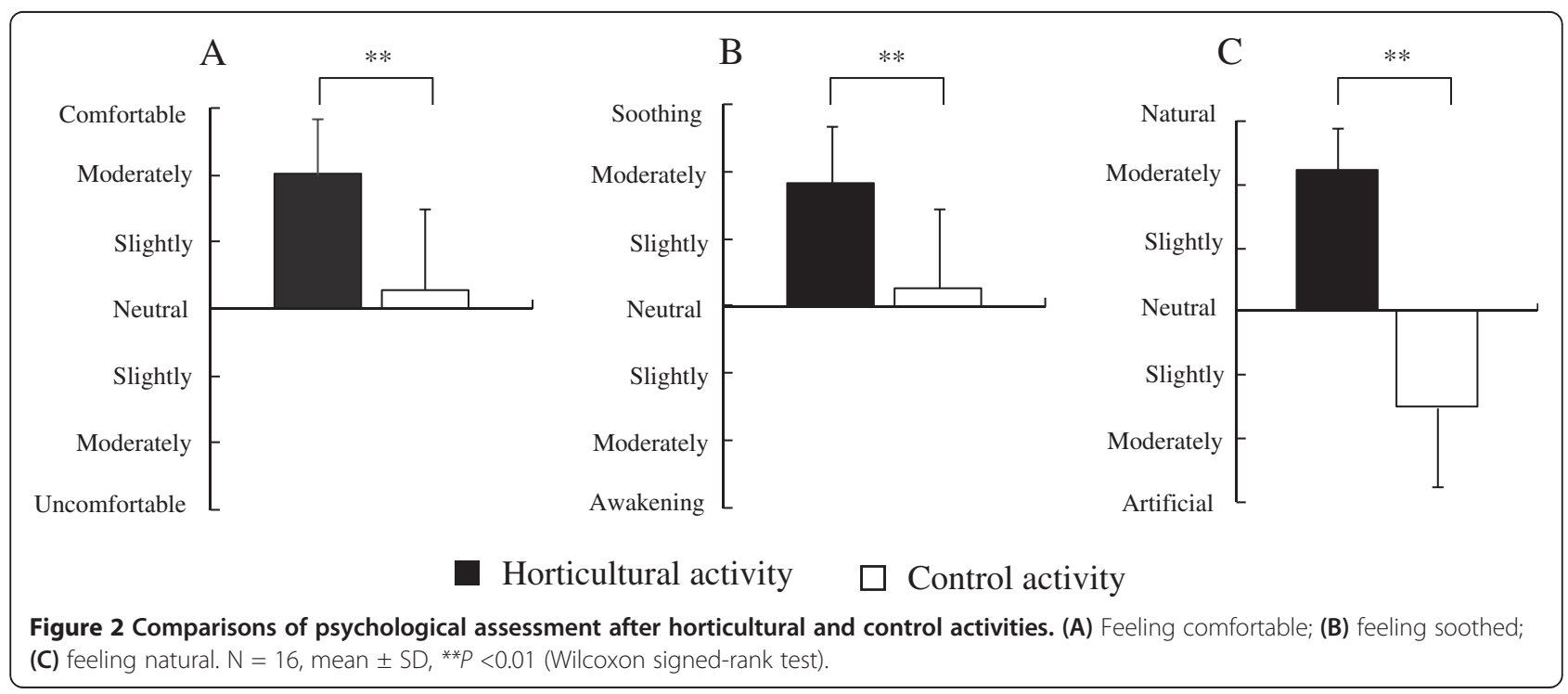



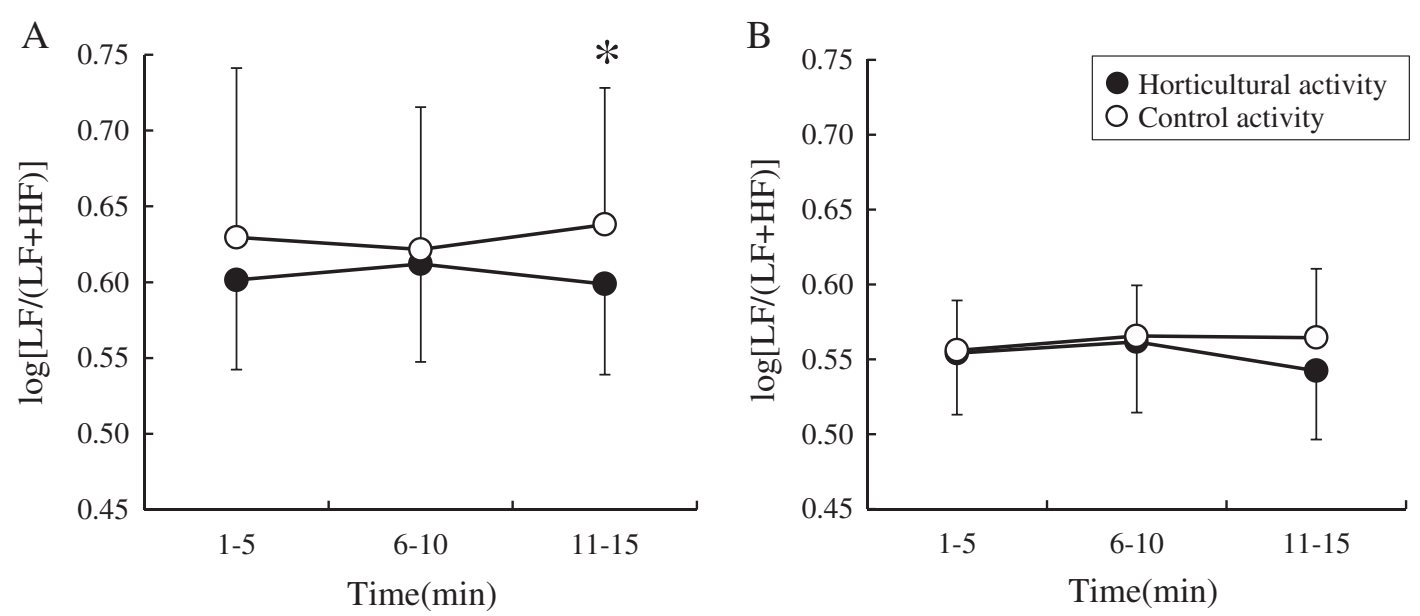

Figure 3 Comparison of the values of $\log (\mathrm{LF} /(\mathrm{LF}+\mathrm{HF}))$ during a 15 -minute horticultural and control activities using two-way repeated measures analysis of variance (ANOVA). Mean $\pm S D$. (A) Type A group $(N=8)$; ${ }^{*}<<0.05$; (B) type B group $(N=8)$; not significant. $H F=$ high frequency, LF = low frequency.

\section{Discussion}

We examined the relaxing effects of a horticultural activity by measuring physiological and psychological changes based on the comparison of a transplanting activity using real and artificial flowers. Based on the subjective evaluation, participants felt more comfortable, soothed, and natural when transplanting real flowers compared to artificial flowers. The apparent psychological effects of horticultural activity are in part consistent with previous research related to natural stimuli [3,24-27].

Analysis of the physiological responses revealed differences in the effects of horticultural activities in the type A group. This group showed a significantly decreased sympathetic nervous response to the late time period of the horticultural activity compared to the control activity; however, the type B group revealed no significant changes. Decreased sympathetic nervous activity indicates that physiological tension or stress has eased, which is linked to physiological relaxation. The physiological data supports the fact that horticultural activity using natural materials can facilitate physiological relaxation by reducing sympathetic nervous activity [28], and these physiological benefits can differ among individuals depending on the type A personality $[13,14,29]$. This finding indicates that analysis of individual differences based on the type A personality might provide clues in considering physiological polymorphism, as reported in a previous study [13]. Although the reason why the physiological benefits occurred after 11 minutes of horticultural activity is not clear, this beneficial effect may be associated with nature-oriented stimulations including living flowers [30].
Despite the limitations in methodology including a lack of baseline data and a limited participant group, our findings provide insights for future research directions in related areas based on the perspective of physiological anthropology.

This study supports the fact that horticultural activity enhances not only the psychological state by increasing positive feelings but also physiological relaxation by reducing sympathetic nervous activity. In particular, the physiological benefits of horticultural activity can differ among individuals with different personalities.

\section{Competing interests}

The authors declare that they have no competing interests.

\section{Authors' contributions}

ML participated in the study design, carried out data collection and analysis, and drafted the manuscript, BP participated in the study design and carried out data collection and interpretation, JyL participated in the study design and carried out data collection and analysis, KP carried out data collection and analysis, JK participated in the study design and data interpretation, JWL participated in study design and data interpretation, $\mathrm{KO}$ participated in data interpretation and helped to prepare the manuscript, and YM participated in the study design and data interpretation and improved the manuscript. All authors read and approved the final manuscript.

\section{Author details}

${ }^{1}$ Center for Environment, Health and Field Sciences, Chiba University, Kashiwa, Japan. ${ }^{2}$ Department of Environment and Forest Resources, Chungnam National University, Daejeon, Korea. ${ }^{3}$ Korea Forest Service, Government Complex 1, Daejeon, Korea. ${ }^{4}$ Department of Horticulture, Chungnam National University, Daejeon, Korea. ${ }^{5}$ Department of Nursing, Chungnam National University, Daejeon, Korea.

Received: 13 June 2012 Accepted: 24 September 2013 Published: 10 October 2013 


\section{References}

1. Miyazaki Y, Park BJ, Lee J: Nature therapy. In Designing Our Future: Local Perspectives on Bioproduction, Ecosystems and Humanity (Sustainability Science). 4th edition. Edited by Osaki M, Braimoh A, Nakagami K. Tokyo, Japan: United Nations University Press; 2011:407-412.

2. Wilson EO: Biophilia: The Human Bond with Other Species. Cambridge, MA: Harvard University Press; 1984.

3. Kaplan R, Kaplan S: The Experience of Nature: A Psychological Perspective. Cambridge, UK: Cambridge University Press; 1989.

4. Kaplan S: The restorative benefits of nature: toward an integrative framework. J Environ Psych 1995, 15:169-182.

5. Ulrich RS, Simons RF, Losito BD, Fiorito E, Miles MA, Zelson M: Stress recovery during exposure to natural and urban environments. J Environ Psych 1991, 11:201-230.

6. Frumkin $\mathrm{H}$ : Beyond toxicity, human health, and the natural environment. Am J Prev Med 2001, 20:234-240.

7. Cammack C, Waliczek TM, Zajicek JM: The green brigade: the psychological effects of a community-based horticultural program on the self-development characteristics of juvenile offenders. Hort Technol 2002, 12:82-86.

8. Cimprich B: Development of an intervention to restore attention in cancer patients. Cancer Nurs 1993, 16:83-92.

9. Matthew W, Jonathan W, François H, Ana M, Mariano R: Effects of horticultural therapy on mood and heart rate in patients participating in an inpatient cardiopulmonary rehabilitation program. I Cardiopulm Rehab 2005, 25:270-274.

10. Kim E, Mattson RH, Park S, Lunday L, Knigge A: Horticultural therapy program for cancer survivors: current status in the United States and a pilot research program. Acta Hort 2008, 790:129-131.

11. Adachi M, Rode CLE, Kendle AD: Effects of floral and foliage displays on human emotions. Hort Sci 2000, 10:59-63.

12. Ewen RB: An Introduction to Theories of Personality. Mahwah, NJ: Lawrence Erlbaum Associates; 2003

13. Miyazaki Y, Tsunetugu Y: A tentative proposal on physiological polymorphism and its experimental approaches. J Physiol Anthropol Appl Human Sci 2005, 24:297-300.

14. Park BJ, Morikawa T, Ogata T, Washide K, Iwamoto M, Nakamura H, Miyazaki $Y$ : Psychological effects of ingesting eucalyptus essential oil with milk casein peptide. Silva Fenn 2009, 43:173-179.

15. Friedman M, Rosenman RH: Type A Behavior Pattern and Your Heart. New York, NY: Knopf Press; 1974

16. Jenkins CD, Rosenman RH, Zyzanski SJ: Prediction of clinical coronary heart disease by a test for the coronary-prone behavior pattern. N Engl J Med 1974, 290:1271-1275.

17. Task Force of the European Society of Cardiology and the North American Society of Pacing and Electrophysiology: Heart rate variability: standards of measurement, physiological interpretation and clinical use. Circulation 1996, 93:1043-1065.

18. Cacioppo JT, Berntson GG, Binkley PF, Quigley KS, Uchino BN, Fieldstone A: Autonomic cardiac control. II. Noninvasive indices and basal response as revealed by autonomic blockades. Psychophysiol 1994, 31:586-598.

19. Weise F, Heydenreich F: Effects of modified respiratory rhythm on heart rate variability during active orthostatic load. Biomed Biochim Acta 1989, 48:549-556.

20. Haynes SG, Levin S, Scotch N, Feinleib M, Kannel WB: The relationship of psychosocial factors to coronary heart disease in the Framingham study: I. Methods and risk factors. Am J Epidemiol 1978, 107:362-384.

21. McCranie EW, Simpson ME, Stevens JS: Type A behavior, filed dependence, and serum lipids. Psychosom Med 1981, 43:107-116.

22. Taylor $\mathrm{H}$, Cooper $\mathrm{CL}$ : The stress-prone personality: a review of the research in the context of occupational stress. Stress Med 1989, 5:17-27.

23. Son YJ, Yang YR, Kwon HY, Lee YK, Lee JH, Lee EM, Xu Z, Chang MH, Cho SI: The association between type $\mathrm{A}$ behavior pattern and hypertension among adults in a rural area (In Korean). Korean J Public Health 2001, 38:72-83.

24. Lohr VI, Person-Mins CH: Physical discomfort may be reduced in the presence of interior plants. Hort Technol 2000, 10:53-58.

25. Tsunetsugu Y, Park BJ, Ishii H, Hirano H, Kagawa T, Miyazaki Y: Physiological effects of "Shinrin-yoku" (taking in the atmosphere of the forest) in an old-growth broadleaf forest in Yamagata prefecture, Japan. J Physiol Anthropol 2007, 26:135-142.
26. Park BJ, Tsunetsugu Y, Ishii H, Furuhashi S, Hirano H, Kagawa T, Miyazaki Y: Physiological effects of shinrin-yoku (taking in the atmosphere of the forest) in a mixed forest in Shinano town, Japan. Scand J Forest Res 2008, 23:278-283.

27. Lee J, Park BJ, Tsunetsugu Y, Ohira T, Kagawa T, Miyazaki Y: Effect of forest bathing on physiological and psychological responses in young Japanese male subjects. Public Health 2011, 125:93-100.

28. Hoffman JW, Benson H, Arns PA, Stainbrook GL, Landsberg GL, Young JB, Gill A: Reduced sympathetic nervous system responsivity associated with the relaxation response. Science 1982, 215:190-192.

29. Spector $\mathrm{PE}, \mathrm{O}^{\prime} \mathrm{C}$ onnell $\mathrm{BJ}$ : The contribution of personality traits, negative affectivity, locus of control and type $A$ to the subsequent reports of job stressors and job strains. J Occup Organ Psychol 1994, 67:1-12.

30. Barnicle T, Midden KS: The effects of a horticulture activity program on the psychological well-being of older people in a long-term care facility. Hort Technol 2003, 13:81-85.

doi:10.1186/1880-6805-32-15

Cite this article as: Lee et al: Physiological relaxation induced by horticultural activity: transplanting work using flowering plants. Journal of Physiological Anthropology 2013 32:15.

\section{Submit your next manuscript to BioMed Central and take full advantage of:}

- Convenient online submission

- Thorough peer review

- No space constraints or color figure charges

- Immediate publication on acceptance

- Inclusion in PubMed, CAS, Scopus and Google Scholar

- Research which is freely available for redistribution
Biomed Central 